\title{
A questão do currículo em tempos sombrios: Hannah Arendt, W. G. Sebald e professores como sujeitos autobiográficos
}

\section{The question of the curriculum in dark times: Hannah Arendt, W. G. Sebald, and teachers as autobiographical subjects}

La cuestión del currículo en tiempos oscuros: Hannah Arendt, W. G. Sebald y los docentes como sujetos autobiográficos

Teresa Strong-Wilson ${ }^{1}$

DOI: http://dx.doi.org/10.20435/serie-estudos.v0i0.1500

\begin{abstract}
Resumo: Este artigo explora as interseções entre as escritas de Arendt sobre vidas e a versão de Sebald da vida-escrita, buscando refletir sobre como essas interseções contribuem para a questão do sujeito autobiográfico nos estudos curriculares conforme pertencem ao discernimento da relação entre pensamento e juízo. Argumenta como questões recorrentes da educação atual, como a redução dos professores e alunos a números, instrumentos, comportamentos, servem a dado propósito. Conclui afirmando que, em termos curriculares, esse discernimento e comprometimento nos leva de volta à reconstrução subjetiva.
\end{abstract}

Palavras-chave: políticas de currículo; autobiografia; sujeito.

\begin{abstract}
This article explores the intersections between Arendt's writings on lives and Sebald's version of life-writing, looking to reflect on how these intersections contribute to the issue of the autobiographical subject in curriculum studies as it pertains to the discernment of the relationship between thought and judgment. It argues how recurrent issues of current education, such as reducing teachers and students to numbers, instruments, behaviors, serve a given purpose. It concludes by affirming that, in curricular terms, this discernment and commitment takes us back to subjective reconstruction.
\end{abstract}

Keywords: curriculum policies; autobiography; subject.

Resumen: Este artículo explora las intersecciones entre los escritos de Arendt sobre vidas y la versión de Sebald de la escritura de la vida, buscando reflexionar sobre cómo estas intersecciones

\footnotetext{
${ }^{1}$ Universidade de McGill, Canadá.
} 
contribuyen al tema autobiográfico en los estudios curriculares conforme pertenecen al discernimiento de la relación entre pensamiento y juicio. Argumenta cómo los problemas recurrentes de la educación actual, como la reducción de maestros y estudiantes a números, instrumentos, cumplen un propósito determinado. Concluye afirmando que, em términos curriculares, este discernimiento y compromiso nos lleva de vuelta a la reconstrucción subjetiva.

Palabras clave: políticas curriculares; autobiografía; sujeto.

\section{INTRODUÇÃO}

O problema em estudar o currículo, como Madeleine Grumet (1991) apontou, é que nós somos o currículo. William Pinar (2011) nos lembrou sobre o duplo sentido em que a "questão do sujeito" em estudos sobre currículo está baseada: currículo como objeto de pesquisa, mas também preocupado com o sujeito como aprendiz individualizado. Esse duplo sentido, sugere Pinar, indica a "consciência dupla" ou alegórica do currículo (PINAR, 2011, p. 141). Em uma alegoria, enquanto uma história específica é contada, outra mais genérica também é transmitida (PINAR, 2011). Que tipos de histórias estão sendo contadas atualmente nos estudos curriculares? E com que implicações para professores enquanto sujeitos?

A história dominante nesses "tempos sombrios" (ARENDT, 1968) concentra-se em testes, com frequentes casos de: avaliações baseadas apenas em resultados e aprendizagem de estudantes reduzida a números. Por fim, resulta no uso de notas para aumentar ou diminuir os recursos escolares, com implicações terríveis para a escola, professores e estudantes, que podem ser prejudicados por metas preestabelecidas e professores vistos como "funcionários" (ARENDT, 1958; GREENE, 1971; 1995) premiados, ou punidos, pelos resultados dos estudantes (AU, 2011; RUBIN, 2011). Como alternativa, continuamente murmurante, a história nos estudos curriculares mostra uma imagem mais complicada, trata-se de uma importante vertente que foi articulada por meio de autobiografia.

Houve uma explosão no número de publicação de livros de memórias nas últimas duas décadas. Tanto que, mesmo em tempos austeros, com livrarias fechando por todo canto, as que permanecem abertas notoriamente apresentam seções de biografias e autobiografias. Se há autores de livros de memórias, deve haver leitores.

É, de fato, muito provável que o desejo de ler auto/biografias de outros seja um reflexo espontâneo do desejo do eu narrável pela narração... o que orienta essa busca é apenas a convicção de que a vida de cada eu narrável 
A questão do currículo em tempos sombrios: Hannah Arendt, W. G. Sebald e professores como sujeitos autobiográficos

representa uma história que pode ser contada. (CARAVERO, 2000, p. 74, tradução nossa) $)^{2}$.

Mas quem ou o que é um eu narrável? Dois autores que consideraram essa pergunta em "tempos sombrios" são Hannah Arendt e W. G. Sebald. O termo "Tempos sombrios" aparece no título de um dos livros de Arendt (1968).

Os lineamentos da história de vida de Hannah Arendt (1906-1975) e W. G. Sebald (1944-2001) são amplos e familiares àqueles que conhecem seus trabalhos: um estudando o domínio da filosofia política, e o outro, a crítica literária e social. Arendt e Sebald deixaram a Alemanha e viveram, por muito tempo, exilados de sua terra natal. Uma (Arendt) no início do que se tornou uma sequência catastrófica de eventos, e o outro (Sebald) nascido no fim do terceiro Reich; logo, herdando com o nascimento "a indelével, inescapável, recorrente e hediondamente recuperável 1944", que marcaria o curso de sua vida (OZICK, 1966, p. 34). Arendt se importa muito com começos, enquanto Sebald se preocupa com finais: "o fenômeno do suicídio na velhice" (SEBALD apud KATAFOU, 1998, p. 33), causado pelos efeitos em longo prazo de traumas.

Apesar de nenhum dos estudiosos se dedicar a estudos curriculares, ambos escreveram, pensaram e refletiram sobre aspectos cada vez mais reconhecidos como pertinentes à educação e, principalmente, a educadores (e.g.: Hansen, 2012; Joldersma, 2014). No centro do interesse, para muitos estudos curriculares, o sujeito, um indivíduo, alguém que está atualmente "perdido na ação", como William Pinar (2011, p. xi) reiterou recentemente. Isto é assim, ainda que o fato da ação repouse na questão da natalidade: para Arendt, com o nascimento, alguém aparece no mundo, alguém distinto de todo outro ser que o/a precedeu ou sucederá e sobre quem uma história pode ser contada.

A história real, em que nos engajamos durante toda a vida, não tem criador visível nem invisível porque não é criada. O único 'alguém' que ela revela é o seu herói; e ela é o único meio pelo qual a manifestação originalmente intangível de um 'quem' singularmente diferente pode tornar-se tangível ex post facto através da ação e do discurso. (ARENDT, 1958/1998, p. 186).

\footnotetext{
2 "It is indeed quite probable that the desire to read auto/biographies of others is a sort of spontaneous reflex of the narratable self's desire for narration... what orients this search is simply the conviction that each narratable self has a life about which a story can be narrated" (Tradução livre, NT).
} 
Quando W. G. Sebald saiu da academia para ficção em prosa, contava histórias da vida das pessoas baseadas em indivíduos reais que ele tinha conhecido ou ouvido sobre, cujas vidas tinham sido profundamente afetadas pelo que viveram e testemunharam no despertar da guerra (particularmente do Nazismo). Embora a maior parte da atenção em Hannah Arendt tenha se concentrado em sua escrita política (totalitarismo, violência, revoluções) e em pensamento/juízo, ela também escreveu histórias de forma apaixonada e atenciosa. Uma das suas grandes contribuições nesse domínio foi a insistência, nada pós-moderna, de que a vida precede qualquer história contada sobre ela. Ou seja, o texto é secundário. Sebald foi aclamado entre os autores modernistas mais textuais e intertextuais, sendo frequentemente considerado pós-moderno, tanto em sensibilidade quanto em estilo. Ainda assim, a saliência do ano de nascimento de Sebald e dos tipos de história que persistentemente escolheu está conectada a uma rede de indivíduos reais. No pós-guerra, Sebald provavelmente contribuiu para a escrita de histórias enquanto forma de pensar, tal como Hannah Arendt nos ajudou a teorizar sobre as conexões entre ação, juízo e histórias narradas.

Neste artigo, exploro as interseções entre as escritas de Arendt, sobre vidas, e a versão de Sebald da vida-escrita, buscando refletir sobre como essas interseções contribuem para a questão do sujeito autobiográfico nos estudos curriculares, conforme pertencem ao discernimento da relação entre pensamento e juízo. Assim, considerarei as implicações dessas interseções para o professor como sujeito autobiográfico em tempos sombrios.

\section{COMEÇOS (ARENDT)}

Ao traçar a raiz do verbo "agir" em grego e latim, Arendt encontra duas trajetórias diferentes, que dividem o verbo em dois significados. O grego archein significa começar, guiar ou liderar, enquanto em latim o verbo agere significa colocar em movimento (i. e. "guiar"). O verbo grego prattein significa passar, conquistar ou terminar, e o latino gerere, suportar ou concretizar (ARENDT, 1958, p. 189). Arendt comenta que o segundo significado predominou, pois entendemos o verbo agir como conduzir algo à completude. No entanto, Arendt sugere que o significado original da ação como começar ou colocar em movimento é mais próximo da noção de ação como natalidade: quando alguém nasce, um estranho é trazido ao mundo, cujas ações e efeitos a rede de relações humanas não pode prever. 
A questão do currículo em tempos sombrios: Hannah Arendt, W. G. Sebald e professores como sujeitos autobiográficos

Ela identifica três características da rede de relações humanas: imprevisibilidade, fragilidade e intangibilidade. A imprevisibilidade surge da ação e do discurso reveladores: "o agente se revela sem que se conheça a si mesmo ou saiba de antemão quem revela" (ARENDT, 1958, p. 192). A fragilidade das relações humanas acontece porque ações são incontidas, com potencial para "violar todos os limites e transpor todas as fronteiras" (ARENDT, 1958. p. 190). A intangibilidade das relações humanas está relacionada à ação ser a definição sine qua non do que significa ser humano: o domínio das relações humanas é constituído através da pluralidade (o fato de cada pessoa ser distinta das outras), torna-se realidade e mantém-se sustentado por meio das ações de indivíduos.

O conceito de história de Arendt foca nos tipos de história que dizem respeito à narração da vida, o que não nos surpreende, devido ao seu interesse na ação. O primeiro livro escrito por Arendt foi sobre a vida de uma jovem judia, Rahel Varnhagen, que cresceu no fim do século XVIII em Berlim e cujo maior conflito era com sua identidade judia: "Quando se está completamente sozinha é difícil decidir se ser diferente é uma mácula ou uma distinção. Quando não se tem nada para agarrar, você escolhe, por fim, se agarrar ao que lhe distingue dos outros" (ARENDT, 1957, p. 178, tradução nossa) ${ }^{3}$. Arendt depois publicou Homens em Tempos Sombrios, que combina narração com análise de episódios centrais na vida de dez indivíduos (homens e mulheres) que viveram na primeira metade do século XX e foram afetados por "[...] suas catástrofes políticas, seus desastres morais e seu surpreendente desenvolvimento das artes e ciências" (ARENDT, 1968, p. vii). "Mesmo no tempo mais sombrio temos o direito de esperar alguma iluminação", diz Arendt; essa luz pode vir de ideias, mas também "[...] da luz incerta, bruxuleante e frequentemente fraca que alguns homens e mulheres, nas suas vidas e obras, farão brilhar" (ARENDT, 1968, p. ix).

Da ação, começa uma história em que "O problema é que, seja qual for a natureza e o conteúdo da história subsequente - quer transcorra na vida pública ou na vida privada, quer envolva muitos ou poucos atores - seu pleno significado somente se revela quando ela termina" (ARENDT, 1958, p. 192). Portanto cabe a outros contar a história. O conceito de Arendt sobre a escrita da vida apoia-se

3 "When you are all alone it is hard to decide whether being different is a blemish or a distinction. When you have nothing at all to cling to, you choose in the end to cling to the thing that sets you off from others" (Tradução livre, N. T.) 
principalmente no gênero da biografia. A autobiografia, na percepção de Arendt, pode comparar-se à teoria da ação do "homem forte", em que todos os inícios e fins são atribuídos a um único agente, e isso é um mito, porque outros ajudam a concretizar o que um iniciou. Além disso, agentes - aqueles que agem - realizam ações, mas também sofrem, o que significa que somos afetados pelo que fazemos e pelo que os outros fazem. Nos termos de Arendt, autobiografias transformam o agente em criador e apoiam-se no "[...] falso pretexto de um indivíduo que se faz outro de modo a contar sua própria história" (CARAVERO, 2000, p. 84, tradução nossa) ${ }^{4}$. Reitera ainda que os contornos da vida de alguém apenas podem ser vistos por aqueles que estão além de quem a viveu. Não é possível viver a própria vida, em seu fluxo de eventos, e também transformá-la em história.

O princípio é bem ilustrado por Karen Blixen (pseudônimo de Isak Dinesen), cujo trabalho Arendt e Caravero recorrem, ao contar a história de um homem que é acordado no meio da noite por um barulho muito alto e corre para fora, de um lado a outro, até achar e consertar o vazamento no dique. De manhã, as pegadas do caminho percorrido por ele formam uma cegonha. A vida pode emergir assim, como dá a entender a fábula - os tropeços cegos no escuro enquanto alguém dá o seu máximo, até o fim da vida. Ainda assim, tal é a distinção da vida, que algo é deixado para trás. "A vida não pode ser vivida como uma história, porque a história sempre vem depois... aquele que caminha não pode ver a figura deixada por suas pegadas, logo, ele ou ela precisa de outra perspectiva", mais propriamente a de um narrador, "para identificar o desenho" (CARAVERO, 2000, p. 3, tradução nossa) ${ }^{5}$.

\section{EICHMANN}

Eichmann em Jerusalém, de Arendt compartilha com Rahel Varnhagen e Homens em Tempos Sombrios a combinação peculiar de narração e análise que também vemos em outras escritas sobre a vida, como a de Carolyn Steedman. Steedman faz uso do seu ponto de vista de historiadora social em sala de aula para o projeto de escrita sobre sua vida e de sua mãe, combinando narração com

\footnotetext{
4 "[...] strange pretense of a self that makes himself an other in order to be able to tell his own story" (Tradução livre, N. T.)

5 "Life cannot be lived like a story, because the story always comes afterwards... the one who walks on the ground cannot see the figure that his/her footsteps leave behind, and so he/she needs another perspective ... to trace the design" (Tradução livre, N. T.)
} 
A questão do currículo em tempos sombrios: Hannah Arendt, W. G. Sebald e professores como sujeitos autobiográficos

a construção de um argumento em sala. Ela chamou sua narrativa de "estudo de caso": "Estudo de caso apresenta a decadência e ritmo da memória, a estrutura de sonhos, as histórias que pessoas contam ao se explicar para os outros" (STEEDMAN, 2008, p. 21, tradução nossa) ${ }^{6}$.

Eichmann em Jerusalém pode ser um relato, um tratado sobre o mal e muito mais, mas também é um estudo de caso sobre um homem (BENHABIB, 1996). Um estudo de caso que apresenta certas semelhanças com o gênero biografia, ao passo que foca no juízo de Eichmann e o período da sua vida adulta em que aguardava o veredito. Porém também narra os começos de Eichmann, assim como o seu fim, incluindo suas últimas palavras. Arendt se interessou pela forma como Eichmann se explicou ao se encontrar em uma situação complicada em Israel, por conta de suas ações durante a guerra. Escrever sobre a vida de um infrator é arriscado em qualquer circunstância. Laurent Binet (2012) reflete sobre esse problema em $\mathrm{HHhH}$, um relato do assassinato de Reinhard Heydrich, que também narra sua história. Binet interrompe a narrativa com frequência, incluindo metarreflexões sobre como a história poderia ser desenvolvida diferentemente. O interesse real de Binet é a história de Gabcik e a história da resistência Tcheca contada por seu pai, que resultou no assassinato de Heydrich por Gabcik. No formato metafictício de Binet em $\mathrm{HHhH}$, percebemos que o modo como a história é contada pode ser tão importante como a história em si.

Na introdução do posfácio de 1964 adicionado a Eichmann em Jerusalém um ano depois da publicação original (1963), Arendt explica que "esse livro contém um relato de julgamento, e a maior fonte são as transcrições do processo, que foram distribuídas à imprensa em Jerusalém" (ARENDT, 1964, p. 280, ênfase de Arendt) ${ }^{7}$. No entanto, o livro é claramente muito mais do que isso, considerando a acuidade das percepções de Arendt sobre o julgamento e sobre o homem. Arendt conheceu Eichmann e ela dizia: "eu o conheço bem" (ARENDT, 2013, p. 43). Interesso-me por como esse evento (nomeadamente a participação de Arendt no julgamento de Eichmann e sua decisão de relatá-lo) está ligado ao seu interesse na história, por um lado, e ao pensamento e julgamento, por outro.

6 "Case-study presents the ebb and flow of memory, the structure of dreams, the stories that people tell to explain themselves to others" (Tradução livre, N. T.)

7 "[t]his book contains a trial report, and its main source is the transcript of the trial proceedings which was distributed to the press in Jerusalem". (Tradução livre, N. T.). 
Adolf Eichmann se encaixa na descrição de Arendt, em A Condição Humana, quando descreve alguém que estaria melhor ao ter uma pedra enrolada ao pescoço e ser atirado ao mar. A história de Eichmann, autodescrita como "má sorte", tornou-se trágica para milhares de outras pessoas afetadas por suas ações, direta ou indiretamente. A corte israelense descreveu como "crimes cometidos em massa": "o grau de responsabilidade diminui conforme nos afastamos do homem que usa as próprias mãos como instrumento fatal" - julgamento citado em Arendt (2006, p. 246-247; ênfase adicionada por Arendt). Eichmann pode não ter matado, mas foi responsável por transportar incontáveis milhões para a morte. Seria melhor que tivesse uma pedra amarrada ao pescoço e fosse jogado ao mar, porque seu nome e vida tornaram-se, para Arendt, sinônimos da "banalidade do mal" (ARENDT, 2006, p. 252). O subtítulo do livro de Arendt indica que é um "relato", mas que é sobre a tese. Todavia a frase aparece apenas uma vez, na última página do último capítulo, que termina com as últimas palavras de Eichmann depois de subir à forca "com grande dignidade" (ARENDT, 2006, p. 252). Ele diz, Arendt reporta: "Em breve, senhores, nos encontraremos de novo. Tal é o destino de todos os homens. Vida longa à Alemanha, vida longa à Argentina, vida longa à Áustria. Não esquecerei deles" (Idem, p. 252, ênfase de Arendt) ${ }^{8}$. Arendt enfatiza os clichês que, como um refrão ruim, puderam ser percebidos enquanto ele falava no julgamento: "Foi como se naqueles últimos minutos estivesse resumindo a lição que este longo curso de maldade humana nos ensinou - a lição da temível banalidade do mal, que desafia as palavras e os pensamentos" (ARENDT, 2006, p. 252, ênfase de Arendt) ${ }^{9}$.

Teríamos de esperar até $A$ Vida do Espírito para que Arendt se voltasse mais uma vez à relação entre pensamento (sua ausência) e mal. Um assunto referido conceitualmente primeiro em As Origens do Totalitarismo, no qual argumenta que o Nazismo constitui uma nova forma do "mal radical" de Kant (ARENDT, 1951). Em A Vida do Espírito, vê-se que sua reflexão sobre o assunto mudou ao encontrar Eichmann: "Minha preocupação com as atividades espirituais tem origem

\footnotetext{
8 "After a short while, gentlemen, we shall all meet again. Such is the fate of all men. Long live Germany, long live Argentina, long live Austria. I shall not forget them" (Tradução livre, N. T.)

9 "It was as though in those last minutes he was summing up the lesson that this long course in human wickedness had taught us - the lesson of the fearsome, word-and-thought-defying banality of evil" (Tradução livre, N. T.)
} 
A questão do currículo em tempos sombrios: Hannah Arendt, W. G. Sebald e professores como sujeitos autobiográficos

em duas fontes bastante distintas. O impulso imediato derivou do fato de eu ter assistido ao julgamento de Eichmann em Jerusalém" (ARENDT, 1978, p. 3). Arendt então passa a narrar como, embora tenhamos aprendido (na escola, como parte da tradição) que o mal é algo "demoníaco" (Idem, p. 3), em Eichmann, ela foi "confrontada" com algo que:

[...] era inteiramente diferente e, no entanto, inegavelmente factual. O que me deixou aturdida foi que a conspícua superficialidade do agente tornava impossível retraçar o mal contestável de seus atos, em suas raízes ou motivos, em quaisquer níveis mais profundos. Os atos eram monstruosos, mas o agente - ao menos aquele que estava agora em julgamento - era bastante comum, banal e não demoníaco ou monstruoso. (ARENDT, 1978, p. 5-6).

Ser um herói, Arendt explica, originalmente significava se aventurar para fora do esconderijo, da privacidade do ser, "de agir e falar, de inserir-se no mundo e começar uma história própria" (ARENDT, 1958, p. 186). As palavras-chave aqui são "uma história própria". "A última vez que Eichmann se lembrava de ter experimentado algo sozinho foi em setembro de 1941" (ARENDT, 2006, p. 79, tradução nossa $)^{10}$, Arendt observa ironicamente. "À parte desses modestos triunfos, Eichmann só se lembrava de estados de espírito e de frases de efeito que inventara para acompanhá-los (ARENDT, 2006, p. 62, tradução nossa) ${ }^{11}$, uma delas sendo o "alvoroço" que marcou o discurso do seu funeral. Arendt correlacionou intimamente pensamento com juízo; os dois são atividades diferentes, mas mentalmente relacionadas. Pensar, na sua forma mais elementar, envolve o dois-em-um socrático. Sócrates diz ao "cabeça-dura" Hippias que ele deve ser sortudo por retornar à casa e não se deparar com um "colega desagradável" que "contra interroga" tudo que ele diz (ARENDT, 1978, p. 188). Sócrates explica que, ao ir para casa, ele não está sozinho; ele está na companhia de si mesmo. Por fim, Arendt diz que devemos concordar conosco porque precisamos viver conosco. Fazer o contrário é viver uma vida de contradição, como Ricardo III de Shakespeare, que, quando sozinho, encontra-se em guerra ("Então fuja! Mas, o quê, de mim mesmo? É um bom motivo: para que eu não me vingue? Mas, o

10 "The last time Eichmann recalled having tried something on his own was in September, 1941" (Tradução livre, N. T.)

11 "Eichmann remembered only moods and the catch phrases he made up to go with them" (Tradução livre, N. T.) 
quê, vingar-me eu de mim mesmo?"), mas quem, quando na presença de outros como ele, encontra a coragem necessária para cometer crimes: "Consciência é apenas uma palavra que covardes usam" (Shakespeare apud ARENDT, 1978, p. 189). Enquanto Ricardo III pode ter tido momentos em que se sentiu perturbado, no geral, diz Arendt, aqueles que não praticam o diálogo interno continuam como aqueles que não se importam em se contradizer (porque ele não será confrontado com a contradição): "Jamais poderá ou desejará prestar contas do que diz ou faz" (ARENDT, 1978, p. 191).

Pensar, como Arendt se esforça em apontar, é uma atividade; é exame e reexame constantes, a ponto de desfazer pensamentos já concluídos: "Pensar significa que temos que tomar novas decisões cada vez que somos confrontados com alguma dificuldade" (ARENDT, 1978, p. 177). O pensar acontece de portas fechadas, é invisível aos outros, a menos que seja manifestado, por exemplo, pela escrita, o que se dá pela representação. O juízo lida com particulares e com "coisas ao alcance das mãos" (ARENDT, 1978, p. 193). O juízo é a manifestação do pensamento em situações e na vida em si. Consiste "[...] na habilidade de dizer 'isto é errado', 'isto é belo'" (ARENDT, 1978, p. 193). Ao abordar a relação entre pensar e julgar, Arendt explica que pensar é "[...] derivado do efeito libertador do pensamento" (ARENDT, 1978, p. 193). Se pensar possibilita a habilidade de pensar por si mesmo de forma privada e, portanto, recusando, abstendo-se, não seguindo ou não sendo influenciado pela crença de outros, essa atividade "depuradora" é libertadora (ARENDT, 1978, p. 192); permite a expressão política da diferença, a liberdade, permite a expressão política da diferença, o julgamento: dizer "isso é errado" ou "isso é certo", então agir de outra forma diferente da norma.

Em Eichmann em Jerusalém, Arendt ocupa o espaço do narrador que surge posteriormente, para contar a história de Eichmann, diferentemente de como ele a contou nas entrevistas com Sassen na Argentina ou no tribunal (Eichmann ocupou-se de escrever uma biografia na prisão), para salientar o que viu como o aspecto devastador de uma vida não pensante. A história veio a se tornar uma "lição" (ARENDT, 2006, p. 288): um alerta das consequências catastróficas da ausência de pensamento. A inabilidade de Eichmann de imaginar perspectivas além da sua e o isolamento da realidade por conta da obstinação por si mesmo.

Admito que me pergunto se, no calor do momento do julgamento, Eichmann enganou Arendt; se ele estava tão em controle de sua imagem como Arendt 
A questão do currículo em tempos sombrios: Hannah Arendt, W. G. Sebald e professores como sujeitos autobiográficos

relata; se ele tinha consciência do efeito de suas mentiras e como afetavam aos outros; se ele era ou não o criador da Solução Final, o instrumento perfeito deles. Pergunto-me se Arendt foi veemente demais na asserção de que Eichmann não tinha uma ideologia própria. Eu li a versão em inglês da transcrição da entrevista, feita antes do julgamento pelo investigador israelense Avner Less, com Eichmann (EICHMANN \& VAN LANG, 1983). Também considero livros recentes como Eichmann Before Jerusalem, da acadêmica alemã Betina Stangneth (2014), que é baseado em documentos aos quais Arendt não poderia ter acesso quando escreveu. Pergunto-me se a avaliação de Eichmann feita por Arendt é um julgamento sem considerar um panorama mais completo, e se ela simplesmente não aceitou mudar de ideia quando questionada. Ainda não tenho uma resposta definitiva para minhas perguntas. No entanto, sei que Arendt admitiu ter reexaminado sua opinião em relação à banalidade de Eichmann enquanto enfrentava diretamente o ceticismo, até daqueles em que confiava, como seu mentor, Karl Jaspers (YOUNG-BUREHL, 2004). É útil comparar a perspectiva de Arendt com a de W. G. Sebald, outro escritor e acadêmico alemão, também muito preocupado com questões relacionadas ao Holocausto e cujas histórias, baseadas em vidas reais, tornaram-se centrais na reflexão sobre perguntas difíceis.

\section{FINS (SEBALD)}

Sebald escreve de forma posterior: daquele que vem depois, que sabe ser tarde demais para mudar as coisas, todavia mantém o pensamento sempre tentando alcançar algum entendimento do significado de eventos dolorosos ao lembrar e ouvir sobre. Sebald escreve na zona cinzenta que Cathy Caruth (1995) chamou de atraso, ou intervalo, do trauma. Ele se interessou pelo fenômeno do suicídio na velhice: a densidade adquirida pela memória conforme o tempo passa. O que contribui para essa densidade são "coincidências" ou congruências: os anos acumulados de fatos, pensamentos e emoções adjacentes e relacionados. A sensação de que tudo está inter-relacionado cresce cada vez mais, até que o entendimento começa a cristalizar e, ao cristalizar, surge a ameaça de se desfazer: não obstante da imagem do pensamento segundo Arendt.

O interesse de Sebald em vidas é posterior ao seu interesse em histórias. Durante a maior parte de sua vida adulta, foi um acadêmico literário. Seu trabalho acadêmico, mestrado e doutorado, baseou-se em autores alemães de ficção do 
pós-guerra, que ele certamente leu e mergulhou nas histórias. Sebald começou seus estudos na Alemanha, mas mudou-se rapidamente para Suíça, não conseguindo suportar a atmosfera intelectual da universidade alemã no pós-guerra. Depois, aceitou um cargo na Universidade de East Anglia, no Reino Unido, e continuou ensinando no local pelo restante de sua vida, exilado da sua terra natal, Alemanha, com exceção de visitas periódicas. Em 1997, retornou à Alemanha para uma série de palestras que foram publicadas como História Natural da Destruição. Um dos tópicos principais das palestras é a literatura alemã do pós-guerra e, consequentemente, a Alemanha em si e sua responsabilidade. Sebald comenta:

Quando olhamos para trás, em particular para anos de 1930 a 1950, é sempre com um olhar que ao mesmo tempo se foca e se desvia. As produções dos autores alemães do pós-guerra são por isso marcadas por uma meia consciência ou falsa consciência destinada a consolidar a posição extremamente precária dos escritores numa sociedade que, normalmente, está de todo desacreditada. (SEBALD, 1997, p. 8).

Ao dizer "meia" ou "falsa" consciência, Sebald se refere ao "negócio" de encobrir o legado e o fardo do passado, em que muitos estavam implicados. Como Arendt observa sobre a Alemanha no pós-guerra, admissões coletivas de culpa serviram para "[...] encobrir... aqueles que fizeram algo... onde todos são culpados, por fim, ninguém é" (ARENDT, 2003, p. 28, tradução nossa) ${ }^{12}$, e muitos daqueles no governo ou nos negócios que estavam no poder ou se beneficiaram durante a guerra discretamente mantiveram as mesmas condições depois. Arendt exemplifica com o caso dos funcionários públicos que Hitler herdou da República Weimar e que Adenauer herdou dos nazistas "sem muita dificuldade" (ARENDT, 2003, p. 35). Posteriormente, Sebald trocou a crítica literária acadêmica pela escrita de ficção em prosa, e a sua própria escrita se tornou um estudo sobre como escrever auto/biograficamente "a partir de um ponto de vista particular", mas com consciência do peso de assuntos que alemães do pós-guerra estavam evitando, ou apenas fingindo abordar. Faço uma pausa aqui antes de seu relato sobre Alfred Andersch, um autor alemão do período pós-guerra, popular e bem-sucedido, que apresenta uma semelhança excepcional com Eichmann, de Arendt.

12 "[...] whitewash ... those who had done something... where all are guilty, no one is" (Tradução livre, N. T.) 
A questão do currículo em tempos sombrios: Hannah Arendt, W. G. Sebald e professores como sujeitos autobiográficos

\section{ANDERSCH}

Andersch foi um radialista, editor e, por fim, novelista. Nascido em 1914, em Munique, foi detido brevemente em Dachau, por três meses; mas, em vez de se mudar para Suíça, permaneceu na Alemanha, adotando posteriormente o epíteto de emigrante interno. Eram considerados emigrantes internos aqueles que moravam na Alemanha no período nazista, mas não participavam, estavam em exílio e em resistência de todas as formas, menos física e geográfica. No entanto, Sebald questiona sua postura, indicando o trabalho de Andersch em Verlagbuchhandlung, de Lehmann, editor que abertamente apoiava as políticas nazistas de raça e "higiene racial" (p. 116).

Sebald retrata Andersch como ambicioso, um oportunista que se casou com uma mulher judia para protegê-la ostensivamente das leis de Nuremberg, mas cuja família também era muito rica. Um ano depois, em junho de 1942, quando a Solução Final estava sendo implementada, divorciou-se dela enquanto se candidatava para ser membro de um clube de escritores da elite alemã (Câmara de Literatura do Reich), deixando sua esposa numa posição precária. Andersch foi chamado para o front, candidatando-se a um "emprego confortável no Ministério do $\mathrm{Ar}^{\prime \prime}$, mas acabou em uma unidade diferente (p. 122). Ele foi agradavelmente surpreendido com a ida à guerra: andando de moto pela Itália, bebendo Chianti nas pequenas vilas: "turismo de guerra" (p. 123). Sebald cita as cartas publicadas de Andersch: "É incrível... pensar em tudo que vi esse ano" (SEBALD, p. 123). Andersch de Sebald soa espantosamente como a descrição de Eichmann por Arendt, alguém comovido pela própria experiência e que não consegue ver além de si mesmo. A mesma palavra "euforia" reaparece: "Andersch não foi o único alemão de classe média a sentir certa euforia na experiência [da guerra]" (SEBALD, p. 123, tradução nossa) $)^{13}$.

Provavelmente, a crítica mais condenatória de Sebald a Andersch é sobre a sua ficção publicada no pós-guerra, que contém certas infelicidades linguísticas, mesmo que Andersch estivesse tentando se reinventar como o próximo grande escritor alemão e expoente de uma "estética nova" (SEBALD, p. 131). No romance de Andersch, Die Rote, Sebald ironicamente nota que, apesar de ter como tema

13 "Andersch was not the only middle-class German citizen to feel a certain elation in the [war] experience" (Tradução livre, N. T.) 
o "notório passado" da Alemanha, o livro usa "Auschwitz como contexto para criar o cenário" de uma forma que Sebald considera obscena (Idem, p. 134). Em seu primeiro romance, o herói, Gregor, apaixona-se por uma menina judia, que é descrita por meio de suas características raciais, inseridas no texto para justificar a atração inexplicável de Gregor. Sebald aponta o uso do jargão alemão na prosa de Andersch, que força os limites com frases que continuaram populares de forma inapropriada depois da guerra: "Efraim está numa festa com Anna quando escuta alguém, que não tinha conhecido antes, dizendo que pretende continuar se alegrando 'bis zur Vergasung' ('até ser sufocado por gás'), uma frase alemã conhecida, ainda muito usada nos anos pós-guerra e que deve ter sido inserida no vocabulário popular na década de 40" (SEBALD, p. 137).

\section{UNRECOUNTED}

Durante as palestras da História Natural da Destruição, Sebald está reagindo à decrepitude moral que vê em muitos autores alemães do pós-guerra, ao mesmo tempo que busca, inconscientemente, a forma que sua fiç̧ão em prosa auto/biográfica vai tomar. Há diversas características da ficção em prosa de Sebald que são relevantes para a discussão da relação entre vidas e histórias. As histórias de Sebald são baseadas na vida de pessoas reais. As vidas que abordava consistentemente são de pessoas afetadas pelo contato com políticas e práticas nazistas. Vidas não existem independentes umas das outras, mas (como na rede de pluralidade humana de Arendt) são impactadas, direta ou indiretamente, pelos encontros com outras. Os fenômenos da coincidência e da continuidade permeiam sua escrita. Isso contribui para o efeito de "aninhamento" em suas narrativas, técnica que aprendeu com outros autores (e.g.: Thomas Barnhardt, autor austríaco).

Uma responsabilidade pessoal é inserida por meio da presença do narrador, alguém que é um viajante e um andarilho, que é supreendentemente parecido com Sebald, e cujas questões (auto)biográficas informam a narrativa. Ao longo de suas escritas, está a prática de escrever sobre assuntos difíceis, "o assunto invisível" - aquele que o leitor sente a presença na mente do autor. Trata-se de uma estrutura de "escrever a partir de um ponto de vista particular", usando por exemplo a técnica de aninhamento, de forma que a noção de que há algo errado é construída de forma lenta e implacável (STRONG-WILSON, 2015). 
A questão do currículo em tempos sombrios: Hannah Arendt, W. G. Sebald e professores como sujeitos autobiográficos

Ao escrever desta forma, Sebald propositalmente marca seu afastamento dos escritores alemães do pós-guerra, como Andersch, ao mesmo tempo que aborda o peso moral e o fardo de um tema que o preocupou muito e que impactou profundamente sua vida, devido ao lugar e período em que nasceu. A história de um professor do ensino fundamental, Paul Bereyter, foi uma das primeiras narrativas desenvolvidas por Sebald e sinaliza seu interesse na maneira como a vida acaba, a lenta destruição. A história é uma das quatro que compõem sua coleção, Os Emigrantes, sua primeira obra a ser publicada em inglês na América do Norte (SEBALD, 1986). Paul cometeu suicídio ao deitar-se nos trilhos do trem, perto de onde nasceu e de onde ensinou Sebald e seus colegas. Paul tinha descendência judia e terminou sua licenciatura quando as Leis Nuremberg estavam começando a ser implementadas. Então, em vez de ensinar (porque foi impedido), foi exilado na França, onde ficou até seu retorno à Alemanha; serviu no exército (que, na época, era menos exigente ao escolher recrutas) e, então, ensinou na mesma comunidade que o havia banido anos antes. Mais tarde, depois de se aposentar, Paul passou o tempo lendo sobre a vida de outros que cometeram suicídio por conta dos efeitos destrutivos que o Nazismo exerceu em suas vidas. Isso intensificou a perturbação, como sugere Sebald, e levou à escolha de Bereyter de deitar-se nos trilhos e assistir à chegada do trem para levá-lo (assim como levou outros iguais a ele) até a morte. A morte de Sebald foi imprevista, por ataque cardíaco, enquanto dirigia, em 2001.

Muitas obras de Sebald foram publicadas após sua morte. Uma delas é a coleção traduzida para o inglês como Unrecounted, em coautoria com Jan Peter Tripp. Michael Hamburger, que traduziu outras obras de Sebald, aponta que Tripp e Sebald eram contemporâneos e até bons amigos. Ambos cresceram na mesma área, estudaram na mesma escola, foram expostos aos mesmos eventos, e o mais importante, compartilhavam a mesma sensibilidade. Unrecounted é uma coletânea com 33 poemas, haikai, de Sebald e litografias de Tripp. É uma coletânea assombrosa devido à conjunção dos poemas de Sebald (e. g.: "Unrecounted/ always it will remain/the story of the averted/faces" - Sebald \& Tripp, 2004, p. 81, tradução nossa $)^{14}$ com as litografias ardilosas de Tripp, todas compostas de olhos, a maioria de pessoas reais, como Borges e Beckett, até Sebald e Tripp. Os olhos parecem preocupados pensando, discernindo, observando; em alguns

\footnotetext{
14 "Não contadas/sempre permanecerão/a história das faces/afastadas" (Tradução livre, N. T.).
} 
momentos, levemente afastados, porque a visão é difícil de suportar, não obstante a atenção é mantida.

\section{A QUESTÃO DO SUJEITO DOCENTE AUTOBIOGRÁFICO EM TEMPOS SOMBRIOS}

William Pinar (2011), ao revisitar as implicações dos oito anos de pesquisa sobre estudos curriculares, considera a posição de Ralph Tyler, que ele chama de currículo do Dr. Jekyll e Sr. Hyde. A Associação de Educação Progressiva (Progressive Education Association) conduziu um estudo longitudinal sobre currículos em escolas secundárias americanas nos anos 1930. Tyler, o então diretor do Comitê de Avaliação e Registro, aproveitou a ocasião para desenvolver seus princípios sobre currículo e instrução, um volume fino publicado primeiramente em 1949 e reimpresso várias vezes desde então, a última, em 2013. Os quatro "princípios" de Tyler para construção curricular - elaborar objetivos, desenvolver um plano de ensino e aprendizagem, organizar a sala de aula e avaliar o aprendizado dos alunos - têm sido apresentados a novos professores sem reconhecer que esse desenvolvimento curricular representa apenas uma abordagem, e que o método é essencialmente motivado pelo último critério: avaliação (PINAR, 2011). Se avaliação é a ameaça que paira sobre alunos, ela também é sistematicamente aplicada a professores na legislação educacional proposta pela administração Bush, No Child Left Behind ("Nenhuma Criança Deixada para Trás"), seguida da lei do Obama, Race to the Top ("Corrida ao Topo"). O raciocínio de Tyler é baseado no Taylorismo, uma abordagem para gerenciamento de trabalho iniciada em 1910 que buscava otimizar a eficiência econômica. Uma tarefa era dividida em partes, e cada parte atribuída a um trabalhador, que era submetido a uma rotina de trabalho intensa com o objetivo de aumentar a produtividade e, por conseguinte, os lucros da empresa. Tyler traduziu essa abordagem instrumental e de "engenharia social" para o ensino e aprendizagem na sala de aula (PINAR, 2011, p. 83).

Como salientado por Pinar (2011), reformas curriculares podem assumir duas formas: reorganização ou reconstrução. Reorganização "[...] altera o formato institucional segundo o qual conteúdo intelectual é estruturado" (PINAR, 2011, p. 78, tradução nossa) $)^{15}$, e resultados são alterados para o que Pinar chama de

$\overline{15}$ "[...] alters the institutional forms through which the intellectual content is structured" (Tradução 
A questão do currículo em tempos sombrios: Hannah Arendt, W. G. Sebald e professores como sujeitos autobiográficos

"moldes" em que a educação é despejada. O estudo de oito anos, apesar dos objetivos louváveis, era desse tipo (PINAR, 2011); na verdade, a maioria das reformas curriculares se encaixa nesta categoria. Mudanças mais profundas são exigidas pela reconstrução curricular, que reconfigura "[...] conteúdo intelectual à luz de novos conhecimentos", o que leva à "[...] reformulação dos formatos comunicativos e institucionais" 16 , por meio dos quais o conteúdo é promovido (PINAR, 2011, p. 78, tradução nossa). A reconstrução demanda experimentação, na qual professores estejam intelectualmente engajados com o conteúdo e ativamente buscando novas formas de ensiná-lo. Esse tipo de mudança curricular, de reconstrução subjetiva e social, é feita tipicamente por professores, de forma individual ou coletiva, na sala de aula ou por meio de desenvolvimento profissional.

Tyler foi um escritor prudente, permitindo que suas palavras fossem entendidas em uma de duas formas. Na minha aula sobre Fundamentos Curriculares, Tyler é justaposto com Dewey, o que proporciona um contraponto útil. Tyler, como dr. Jekyll, aparece como o colega benigno, afável e progressista, o facilitador que auxilia os professores, que "[...] vê criticamente as consequências de suas ações" (KRIDEL \& BULLOUGH, 2007 apud PINAR, 2001, p. 83). Por meio da observação minuciosa, especialmente em relação a Dewey, que, às vezes, usa as mesmas palavras, mas de forma diferente (e.g.: experiência educacional), Sr. Hyde começa a aparecer: aquele que coloca o professor sob o trabalho do planejador curricular; que caracteriza professores como condições manipuláveis para produzir resultados desejados; para quem os alunos e professores se tornam apenas cifras; um indicador da saúde dos resultados do currículo estadual.

Pinar observa que "[...] o que Tyler 'facilitou' foi a incursão invasiva do behaviorismo nas práticas educacionais dominantes" (PINAR, 2001, p. 84), transformando professores em "burocratas" (PINAR, 2001, p. 85). Essa visão abissal de professores como meros funcionários em um sistema indiferente às necessidades, desejos, sonhos e ambições de alunos e professores foi observada por Maxine Greene no livro Teacher as Stranger, publicado pouco depois de Eichmann em Jerusalém, de Arendt. Greene foi profundamente influenciada pelo trabalho de Arendt e foi a primeira a transpor significativamente as teorias de ação e juízo de

livre, N. T.)

16 "[...] intellectual content in light of new knowledge", "[...] reshaping the communicative and institutional forms" (Tradução livre, N. T.) 
Arendt para a educação. Greene utiliza principalmente a ideia, sugerida por Arendt, de ação como início: o professor como o iniciador. Greene também enfatizou o pensamento do professor como juízo: o professor estando atento e crítico às armadilhas da linguagem curricular, mas também sendo um agente corajoso: alguém que faz mudanças positivas e construtivas por meio de suas ações (WILSON, 2003).

Observar as relações entre a narração da própria história e da história de outros com os atos de discernimento e juízo, especialmente em tempos sombrios, quando professores são submetidos a reorganizações curriculares em vez de serem convidados a participarem da reconstrução curricular, envolve contemplar as narrativas de professores mais de perto - uma tarefa para outro artigo. O espaço aqui me permite apenas indicar brevemente duas narrativas que podem interessar, duas que são seminais no gênero autobiografia de professores: Teacher, de Sylvia Ashton-Warner (1963), e Teacher Man, de Frank McCourt (2005).

Em ambas as histórias, vemos os autores professores buscando um formato e uma linguagem apropriados para narrar o fluxo do ser professor. Percebemos também a dificuldade em lidar com um currículo que restringe e diminuiu o discernimento ao ensinar. Ashton-Warner apresenta uma compilação incomum de narrativa, poesia, fluxo de consciência, pensamentos sonhadores e devaneios, diálogos de sala de aula, descrição curricular e fotografias. Tudo isso centralizado na experiência de Ashton-Warner ensinando crianças Maori muito jovens numa escola primária na Nova Zelândia, em uma época em que a abordagem usada para o ensino de leitura era o uso de livros-texto no padrão britânico com inspetores monitorando a implementação colonial.

Ashton-Warner resiste e desenvolve o que ela chama de abordagem orgânica de leitura baseada em palavras e conceitos significativos para a vida cotidiana das crianças Maori. Maxine Hong Kingston, a notável autora, memorialista e anteriormente professora, escreveu o prefácio da reimpressão de 1986, em que diz: "Na mesma semana que escrevo isso, a administração Reagan está atacando programas de educação bilíngue. De forma urgente, Teacher mostra como respeitar a língua que a criança já fala e como partir disso para o Inglês. Espero que essa republicação motive professores" (KINGSTON, 1986, p. 9, tradução nossa) $)^{17}$.

17 "The very week that I write this, the Reagan administration is attacking bilingual education programs. Urgently, Teacher shows how to respect the language that the child already has, and how to go from there to English. I hope its re-publication gives teachers fuel" (Tradução livre, N. T.) 
A questão do currículo em tempos sombrios: Hannah Arendt, W. G. Sebald e professores como sujeitos autobiográficos

O livro de McCourt é um exemplo mais complexo, enigmático e com os estereótipos e clichês de McCourt sobre a vida de estudantes e de professores ensinando em escolas públicas e privadas entre os anos 1960 e 1980 na cidade de Nova lorque. Há um eco da falsidade dos discursos de Andersch e Eichmann, descritos por Sebald e Arendt, que é trazido pelos encontros de McCourt, com objetivos, planos de aula, livros-texto, regras e restrições, fiscalizadas por diretores e administradores escolares. Observamos isso mesmo enquanto testemunhamos McCourt, genuinamente, tendo dificuldades em ser e se tornar professor apesar do currículo. Às vezes se arrependendo de - mas aprendendo com-suas escolhas improvisadas em sala de aula e cada vez mais passando por situações de epifanias improváveis e maravilhosas sobre ensino, como também, finalmente, relatando o discernimento do amor e do carinho genuíno pelos alunos. Esperamos até quase o final de sua carreira docente e de sua narrativa para o vermos dizendo, falando com o seu eu professor: "Pela maior parte do tempo, a máscara está retirada e consigo respirar" (p. 244). Um "currículo pobre", nos lembra Pinar (2015), é aquele "despido de suas distrações" (PINAR, 2015, p. xiii).

\section{CONCLUSÃO}

Mais do que nunca, discernimento é necessário no ensino: o tipo de discernimento que contribui para a reconstrução subjetiva, e não para um embaralhamento do currículo. Arendt e Sebald, no meio de eventos catastróficos em seus países de origem, analisam criticamente as autodescrições muito comprometidas de pessoas que buscavam avanço pessoal no meio desses períodos e elaboram distinções sobre o que julgam apropriado e inapropriado ao responder a essas situações. Ambos recorrem a formatos biográficos de escrita, Arendt, ao estudo de caso, e Sebald, à ficção em prosa, para investigar a vida dos sujeitos. Arendt, no seu estudo de caso mais famoso, apresenta um relato analítico sobre um infrator, Sebald escolhe narrar a vida daqueles que sofreram. No entanto, a escrita biográfica de Sebald tende consideravelmente para o formato autobiográfico por meio do narrador Sebaldiano, que tem uma semelhança excepcional e visualmente inconfundível com o próprio Sebald. Isso se concilia com a dificuldade do narrador de entender os indivíduos que conhece e as histórias que escuta.

As preocupações de Sebald e Arendt estão presentes no texto como sujeitos tentando processar um tema chocante e sombrio. Para ambos, discernimento é 
essencial, é o que resta quando todas as outras possibilidades já foram consideradas. A ideia está presente nos olhos preocupados e inquisitivos em Unrecounted, de Sebald e Tripp, e na ligação indissociável entre pensamento e juízo de Arendt, com o seu alerta sobre um Eichmann não pensante. Os exemplos narrativos de Arendt e Sebald podem parecer drásticos sob a luz cinzenta da educação atual, mas é um tempo obscurecido por pessoas (professores e alunos) reduzidas a números, instrumentos, comportamentos, servindo a um propósito.

Por trás dos exemplos de cada caso (Arendt e Sebald), há uma teoria que também é um comprometimento pessoal: o discernimento na palavra e na ação. Em termos curriculares, esse discernimento e comprometimento nos leva de volta à reconstrução subjetiva, à "pergunta recorrente sobre o sujeito" (PINAR, 2011), que, como as narrativas autobiográficas de Ashton-Warner e McCourt indicam, anima todo dia as vidas de professores por meio das histórias que contamos ou que acabam sendo contadas por outros que cruzam nosso caminho.

\section{REFERÊNCIAS}

AOKI, T. Curriculum in a new key. Lawrence Erlbaum, 2004.

ARENDT, H. The origins of totalitarianism. Harcourt Brace, 1951.

ARENDT, H. Rahel Varnhagen: The life of a Jewess. London: Publishing for the Institute by the East and West Library, 1957.

ARENDT, H. The human condition. Chicago: University of Chicago Press, 1958.

ARENDT, H. Men in dark times. Harcourt Brace, 1968.

ARENDT, H. The life of the mind. San Diego: Harcourt, 1978.

ARENDT, H. Eichmann in Jerusalem: A report on the banality of evil. New York: Penguin Books, 2006.

ARENDT, H. Responsibility and judgment. New York: Schocken Books, 2003.

ARENDT, H. The last interview, and other conversations. Brooklyn: Melville House. 2013.

ASHTON-WARNER, S. Teacher. New York: Simon and Schuster, 1986. 
A questão do currículo em tempos sombrios: Hannah Arendt, W. G. Sebald e professores como sujeitos autobiográficos

AU, W. Teaching under the new Taylorism: High-stakes testing and the standardization of the 21st century curriculum. Journal of Curriculum Studies, v. 43, n. 1, p. 25-45, 2011.

BENHABIB, S. Identity, perspective and narrative in Hannah Arendt's "Eichmann in Jerusalem." History and Memory, v. 8, n. 2, p. 85-59, 1996.

BINET, L. HHhH. New York: Farrar, Strauss \& Giroux, 2012.

CARUTH, C. Recapturing the past: Introduction. In: CARUTH, C. Trauma: Explorations in memory. Baltimore, Maryland: Johns Hopkins University Press, 1995. p. 151-157.

CAVARERO, A. Relating narratives: Storytelling and selfhood. London: Routledge, 2000.

EICHMANN, A; VON LANG, J. Eichmann interrogated: Transcripts from the archives of the Israeli police. New York: Farrar, Strauss \& Giroux, 1983.

GREENE, M. Teacher as stranger. Belmont, CA: Wadsorth Publishing, 1973.

GREENE, M. Releasing the imagination. San Francisco: Jossey-Bass. 1995.

GRUMET, M. Curriculum and the art of daily life. In: WILLIS, G.; SCHUBERT, W. H. Reflections from the heart of educational inquiry: Understanding curriculum and teaching through the arts. New York: State University of New York Press, 1991. p. 74-89.

HAMBURGER, M. Translator's note. In: SEBALD, W. G.; TRIPP, J. P. Unrecounted. New York: New Directions, 2004. p. 7-12.

HANSEN, D. T. W. G. Sebald and the tasks of ethical and moral remembrance. Philosophy of Education, 2012, p. 125-133.

JOLDERSMA, C. Benjamin's Angel of History and the Work of Mourning in Ethical Remembrance: Understanding the Effect of W. G. Sebald's Novels in the Classroom. Studies in Philosophy and Education, v. 33, p. 135-147, 2014.

KAFATOU, S. An interview with W. G. Sebald. Harvard Review, v. 15, p. 31-35, 1998.

KINGSTON, M. H. Foreword. In: ASHTON-WARNER, S. Teacher. New York: Simon and Schuster, 1984. p. 7-9.

MCCOURT, F. Teacher man. New York: Scribner, 2005.

OZICK, C. The posthumous sublime. The New Republic, 215, n. 25, p. 33-35, 1996. 
PINAR, W. The character of curriculum studies: Bildung, currere, and the recurring question of the subject. New York: Palgrave Macmillan, 2011.

PINAR, W. Preface (1976). In: PINAR, W. F.; GRUMET, M. R. Toward a poor curriculum. Kingston, NY: Educator's International Press. 2015, p. xiii-xvii.

RUBIN, D. I. The disheartened teacher: Living in the age of standardization, high-stakes assessments, and No Child Left Behind (NCLB). Changing English, v. 19, n. 4, p. 407-416, 2011.

SEBALD, W. G. The emigrants. New York: New Directions, 1996.

SEBALD, W. G. Austerlitz. New York: Modern Library, 2001.

SEBALD, W. G. On the natural history of destruction. Toronto: Vintage Canada, 2003.

SEBALD, W. G.; TRIPP, J. P. Unrecounted. New York: New Directions, 2004.

STANGNETH, B. Eichmann before Jerusalem: The unexamined life of a mass murderer. New York: Alfred Knopf, 2014.

STEEDMAN, C. Landscape for a good woman: A story of two lives. New Brunswick, NJ: Rutgers University Press, 2008.

STRONG-WILSON, T. Phantom traces: Exploring a Hermeneutical Approach to Autobiography in Curriculum Studies. Journal of Curriculum Studies, v. 47, n. 5, p. 613632, 2015.

WILSON, T. Maxine's table: Connecting action with imagination in the thought of Maxine Greene and Hannah Arendt. Educational Theory, v. 52, n. 2, p. 203-220, 2003.

YOUNG-BRUEHL, E. Hannah Arendt: For love of the world. New Haven: Yale University Press, 2004.

\section{Sobre a autora:}

Teresa Strong-Wilson: Doutora em Educação e mestre em Educação pela Universidade de Victoria. "Associate Professor" na Universidade de McGill, Canadá, em que faz parte do Departamento de Estudos Integrados em Educação. Áreas de experiência: alfabetização; histórias; autobiografia; metodologias narrativas; educação para justiça social; educação indígena; metodologias participativas; 
pesquisa-ação; documentação e reflexão sobre documentação no ensino; memória; memória de infância; formação estratificada; trabalho de memória; a criança, infância, memória infantil, literatura infantil, abordagem de Reggio Emilia ao pensamento infantil, alfabetização precoce, envolvimento familiar/ alfabetização familiar; teoria do currículo, em particular, currere; os escritos de W. G. Sebald no que diz respeito a currere; professores; pensamento e mudança do professor (incluindo justiça social; tecnologias digitais); desenvolvimento profissional; identidade do professor. E-mail: teresa.strong-wilson@mcgill.ca, Orcid: https://orcid.org/0000-0002-6823-4909

\section{Sobre a tradução:}

O texto foi escrito originalmente na língua inglesa e traduzido para a língua portuguesa por Thayna Pinheiro Ferreira.

Recebido em: 11 de agosto de 2020 Última revisão: 17 de agosto de 2020

Aprovado em: 9 de setembro de 2020 
